\title{
TEACHING FRACTIONS IN ELEMENTARY SCHOOL
}

\author{
An Observational Study
}

\begin{abstract}
A B S T R A C T
This research analyzed how fractions are taught in the fourth grade of elementary school in Flanders. Analysis centered on the presence of five features of instruction recommended by research on teaching and learning fractions (i.e., multiple solution pathways, linking representations, estimation and justification of the solution, collaboration, embedment in a realistic context). Our sample consisted of 88 instructional episodes that were selected out of 24 videotaped lessons and the corresponding lessons in the teacher's guide. Analysis related to instruction as described in the teacher's guide, instruction during the whole group phase of teaching, and instruction during the individual practice phase of teaching. The study revealed (1) that the observed lessons reflected to a limited extend the recommended

instructional features and (2) factors that contributed to a departure from these recommendations. This research is situated in the domain of teaching and learning fractions and within the broader domain of curriculum implementation.
\end{abstract}

\author{
Hendrik Van Steenbrugge \\ MÄLARDALEN UNIVERSITY \\ Janine Remillard \\ UNIVERSITY OF \\ PENNSYLVANIA \\ Lieven Verschaffel \\ KATHOLIEKE \\ UNIVERSITEIT LEUVEN \\ Martin Valcke \\ Annemie Desoete \\ GHENT UNIVERSITY
}

A

S schools function in a constantly evolving society, it should not be a big surprise that curricular goals for mathematics education have changed as well. In order to empower students as mathematically literate citizens, for instance, the focus has shifted over the years from memorizing content and being able to apply procedures toward a conceptual understanding of mathematics and the development of capacities to deal with new mathematical problems. This is

THE ELEMENTARY SCHOOL JOURNAL VOLUME 116, NUMBER 1

(C) 2015 by The University of Chicago. All rights reserved. 0013-5984/2015/11601-0003 $\$ 10.00$ 
reflected in the standards and curriculum programs in several countries. ${ }^{1}$ For example, the National Council of Teachers of Mathematics (NCTM) Standards in the United States describe process standards that focus on problem solving, reasoning and proof, communication, connecting mathematical ideas, and representations of mathematical ideas (NCTM, 2000). Likewise, the standards in Flanders stress the importance of conceptual understanding and underline the usefulness of activities that are embedded in realistic contexts, include problem solving, require students to cooperate and communicate with each other, and encourage students to develop a critical attitude toward numerical information (Ministry of the Flemish Community Department of Education and Training, 1999).

In line with this view on mathematics education, several instructional recommendations have been proposed in research on teaching and learning fractions. However, research has also pointed out that elementary school teachers' knowledge of fractions is rather limited and, in addition, fractions is one of the most challenging topics to teach (Lamon, 2007; Ma, 1999; Newton, 2008). Furthermore, previous research largely focused on teaching and learning whole numbers rather than fractions (Siegler et al., 2010).

Given the evolution in mathematics teaching to a more conceptual understanding, the shortfall on studies on fractions, and the evidence showing that fractions is one of the most difficult math topics to master (both for teachers as for learners), the current study explores the current state of fractions instruction in Flanders. More specifically, the study questions to what extent contemporary recommended instructional features for the teaching of fractions are followed in Flanders. In addition, the study further explores the main rationale for diverting from these main recommendations by investigating curriculum materials and subtopics employed in the curriculum. Given that research on curriculum implementation has shown that one cannot simply look at the representation of the content in curriculum materials (Stein, Remillard, \& Smith, 2007), the way content is taught throughout the lesson will be included as well. In sum, the current study addresses the following research questions: (1) To what extent does the teaching of fractions in Flanders reflect contemporary recommendations from research on the teaching and learning of fractions? (2) What influential factors, including curriculum materials, teaching practices, and the particular content or students in question, contribute to alignment or departure from these recommendations?

\section{Conceptual Framework}

In this section, we first describe the backbone of the conceptual framework (see "Different Phases of Instruction" below). Given its central role, we also include a description of instructional episodes and of the recommended instructional features used to describe the instructional episodes, which is carried out in the subsections "Instructional Episodes" and "Recommended Instructional Features."

\section{Different Phases of Instruction}

There is evidence that teachers use curriculum resources in different ways (Remillard \& Bryans, 2004) and that the character of mathematical tasks can change once unleashed in the classroom (Stein, Grover, \& Henningsen, 1996). These findings underline the necessity of addressing different phases of curricu- 


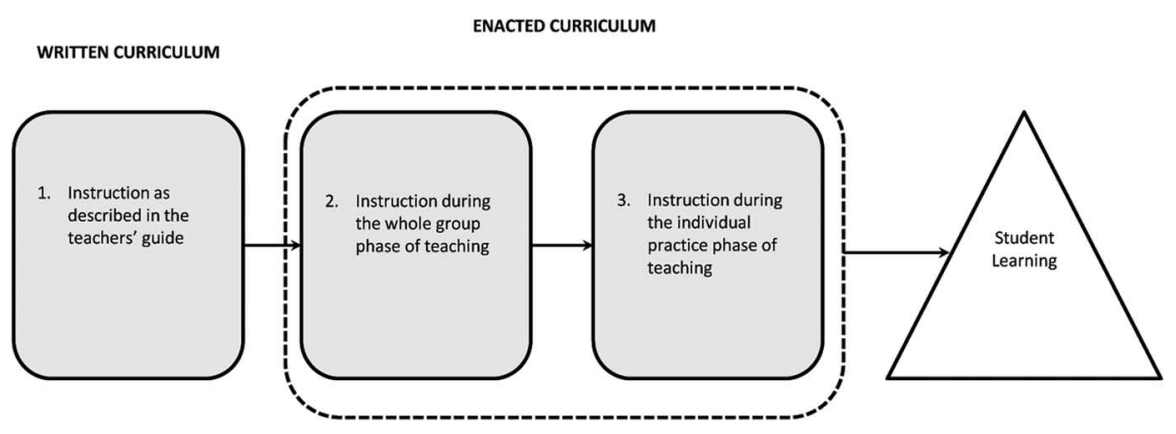

Figure 1. Conceptual framework

lum implementation during a single lesson. Our analysis of this process was guided by a conceptual framework inspired by the mathematics task framework as developed by Stein et al. (1996), but adapted to fit the common lesson structure observed in Flemish classrooms.

Stein et al.'s analysis focused on middle schools seeking to use an instructional approach aligned with the NCTM teaching standards that we did not observe in our schools. Because of the rather fixed structure of the observed Flemish math lessons in a whole class phase and an individual practice phase, we examined these two phases as distinct components of the lesson. Furthermore, the clear distinction between tasks as set up by the teacher and as implemented by students in middle school classes was not apparent in the elementary school classes that we observed. Instruction in our sample of lessons comprised the exchange between the teacher and the student(s) during task implementation. The dominant patterns observed in our sample were (1) instruction as described in the teacher's guide, (2) instruction during the whole group phase of teaching, and (3) instruction during the individual practice phase of the lessons.

This study focuses on three aspects of the conceptual framework (shaded in Fig. 1). Given that curriculum programs are considered to be a main source for classroom instruction (Pepin \& Haggarty, 2001; Stein et al., 2007), a first focus of the study relates to the instruction as described in the teacher's guide. This refers to the way in which instruction to be set up during teaching is described in the teacher's guide. Second, we analyze the instruction during the whole group phase of teaching. This relates to instruction during the learning of new content or refreshment of previously taught content. Typically, this consists of lengthy teacher-directed episodes for the whole group of students. Third, we analyzed instruction during the individual practice phase of teaching. We did so because we observed that the whole group phase of instruction, in general, was followed by an individual practice phase. Students then worked on their own, and the primary focus of the teacher's instructional activity typically centered on individual students who appeared to be having difficulties. The kinds of assistance provided by the teacher to students that are having difficulties is considered to be a factor that influences how tasks are implemented by the students in the classroom (Stein et al., 1996).

\section{Instructional Episodes}

Examination of instruction is framed by means of instructional episodes, a concept that originates from Stein et al.'s (1996) description of mathematical tasks. Stein et al.'s (1996) definition of a mathematical task relates to a classroom activity that 
aims to focus students' attention on a specific mathematical idea. It builds further on Doyle's (1983) notion of academic tasks in that it determines the content that students learn, how students learn this content, and by means of which resources they learn it. Stein and colleagues do not classify an activity as another mathematical task until the underlying mathematical idea changes (Stein et al., 1996, pp. 459-460).

Similar to Stein et al.'s (1996) definition of mathematical task, an instructional episode relates to a specific mathematical idea. Change in this underlying idea is required in order to classify instruction as another instructional episode. What differentiates our approach from the one that Stein et al. (1996) maintained is that we focus on the exchange between the teacher and the student(s) during task implementation. This allows dealing with the absence of a clear distinct pattern between task instruction by the teacher and the implementation by students.

In the current study, instruction during the whole group phase of teaching is typically divided into one or two instructional episodes. This is in accordance with the plea for broader units of analysis to describe the complex nature of teaching (Hiebert \& Grouws, 2007). We should mention, however, that instructional episodes during the individual practice phase of teaching are much shorter. Most often, they consist of an exchange between the teacher and a single student.

A central theme in research related to academic tasks is the extent to which task characteristics can change while passing through the curriculum implementation chain (Stein et al., 1996, p. 460). For example, Stein et al. (1996) found that the cognitive demand of tasks had a tendency to remain the same or decline between setup by the teacher and implementation by the students. ${ }^{2}$ In addition, the likelihood of changing task characteristics between setup and implementation was higher for cognitively demanding tasks when compared to less cognitively demanding tasks. This is an important finding since research also indicated that maintenance of a high level of cognitive demand during lesson enactment was related to higher levels of student learning (Boaler \& Staples, 2008; Stein \& Lane, 1996; Stigler \& Hiebert, 2004). Stein et al. (1996) described several factors considered to be an influence for the decline of cognitive demand. Two important factors were (1) the transition of challenges into nonproblems, either by students pressing the teacher to reduce task complexity or teachers taking over the challenging aspects of the task, and (2) a tendency of teachers to shift the focus from the solution process to the correctness of the answer.

We examined instruction as described in the teacher's guide, during the whole group phase of teaching and during the individual practice phase of teaching on the presence of five recommended instructional features, as described below.

\section{Recommended Instructional Features}

Research has recommended several features of instruction for teaching fractions that are aligned with the current view on mathematics education as described above. Below we describe three studies (Cramer, Post, \& delMas, 2002; Gearhart et al., 1999; Kazemi \& Stipek, 2001) that analyzed reform-oriented curricula when teaching fractions. We also include findings from an extensive review of studies on teaching and learning fractions over the past 20 years (Siegler et al., 2010). This helped to identify recommended instructional features aligned with the current view on mathematics 
education that have the potential to result in better student understanding of fractions.

Gearhart and colleagues studied the effect of curriculum and professional development in a context of teaching fractions in 21 upper elementary classrooms (Gearhart et al., 1999). Data were collected by means of video of lessons on addition of fractions and field notes during lessons on teaching of area and fair-sharing models (problem-solving curriculum) or during typical fractions instruction (traditional curriculum). They also measured student performance by means of a paper-andpencil test before and after the intervention. This test captured students' computational and problem-solving skills related to fractions. To analyze the effect of curriculum, they contrasted a problem-solving curriculum with a traditional curriculum. The problem-solving curriculum enabled the teachers to provide students multiple models for understanding mathematics, pose open-ended and nonroutine questions, have students engage with multiple representations, and encourage group discussion. The traditional curriculum stressed mastery of skills. The study revealed that a problem-solving-oriented curriculum provided significantly more opportunities for students to engage in conceptual discussions built on their understandings compared to the traditional-oriented curriculum. The study also revealed that students in classrooms with more opportunities to engage in conceptual discussions were more likely to improve their problem-solving skills. The study did not provide evidence, however, that the problem-solving curriculum could invoke learning without any support for the teacher.

In another study, Kazemi and Stipek (2001) described how four teachers in grades 4 and 5 of elementary school taught the same lesson on addition of fractions. The intent of the study was to describe situations that go beyond a superficial implementation of the NCTM standards in order to promote conceptual understanding. Videotaped lessons were used to analyze classroom interactions. Their analysis suggested the importance of explanations that consist of a mathematical argument, understanding the relations among multiple strategies, elaborating on errors because they might provide opportunities to reconceptualize problems and explore alternative strategies, and collaborative work that involves individual accountability and reaches consensus through argumentation.

A large-scale study by Cramer et al. (2002) described the effect of using the Rational Numbers Project Curriculum (RNP) on initial fraction learning by fourth- and fifth-grade students in the United States. The RNP curriculum stimulated work with multiple representations, emphasized connections between these representations, and had students regularly interacting with each other in groups. All data were gathered through teacher logs, paper-and-pencil tests, and interviews with students. The results of students exposed to the RNP curriculum were compared against those of students that were taught fractions by means of a traditional commercial curriculum (CC), the primary aim of which was to develop competence at the symbolic level. RNP students outperformed CC students on a number of post- and retention tests. For example, RNP students did better on conceptual understanding of fractions and were better able to transfer their knowledge of fractions to tasks not directly taught to them. Interview data further revealed that answers of RNP students were more conceptually oriented, whereas CC students relied more on procedures. In describing the causes of the observed differences, the authors pointed at the importance of the three above-mentioned features of the RNP curriculum. 
Based on an extensive review of studies over the past 20 years, ${ }^{3}$ the Institute of Educational Sciences, the research arm of the U.S. Department of Education, published a practice guide with recommendations to improve students' understanding of fractions from the age of kindergarten to eighth grade (Siegler et al., 2010). These recommendations reflect the importance of conceptual understanding of fractions and range from proposals related to the development of basic understanding of fractions in young children to more advanced understanding in older students as they progress through elementary and middle school. One recommendation also addresses teachers' own understanding and teaching of fractions. Throughout these descriptions, a number of recommended instructional features recur.

A first recommended instructional feature addresses the importance of building on students' informal understanding. This can be done, for example, by means of equal sharing activities to develop students' understanding of the inverse relation between the number of parts into which a quantity is divided and the size of each part (Sophian, Garyantes, \& Chang, 1997).

Providing opportunities for students to use and discuss alternative strategies is a second recommended instructional feature that is considered important. Siegler et al. (2010) refer to research that has shown that discussing alternative ways to partition and receive the same share-and thus also building on students' informal understanding - is a useful way to understand equivalent shares and ordering of fractions (Empson, 1995; Streefland, 1991).

A third recommended instructional feature relates to the use of visual representations. This is described as having the possibility to contribute to students' conceptual understanding of computational procedures and ratio problems. Siegler et al. (2010) describe the number line as a helpful tool as it helps students to understand equivalent fractions and is useful in locating and comparing fractions. Number lines also help to convey that fractions, decimals, and percentages are numbers that expand the number system beyond whole numbers. Siegler et al. (2010) refer to a study by Rittle-Johnson, Siegler, and Alibali (2001) that found that students' understanding of decimals was related to their ability to locate decimals on a number line.

Providing students opportunities to use estimation to predict or judge the reasonableness of an answer is a fourth recommended instructional feature. Siegler et al. (2010) refer to evidence of a relation between estimation of locations of decimals on a number line and math grades for fifth- and sixth-grade students (Schneider, Grabner, \& Paetsch, 2009).

A fifth recommended instructional feature is the embedment of exercises in realistic contexts. This might awaken students' intuitive problem-solving abilities and help to build further on students' prior knowledge. As an example, Siegler et al. (2010) refer to a study by Irwin (2001) showing that tasks in realistic contexts improved students' ability to order and compare decimals.

It should be mentioned, however, that Siegler et al. (2010) did not find strong empirical evidence for these recommendations. Evidence ranged from minimal to moderate (for a specific description of what counted as minimal, moderate, and strong evidence, see Siegler et al., 2010). Related to this, Hiebert and Grouws (2007) mentioned the difficulty in singling out specific features of teaching and trace mathematics learning gains back to such specific features.

In spite of the absence of strong evidence, we think, based on our review of the literature as described above, that it is reasonable to expect the following recom- 
Table 1. Description of the Five Recommended Instructional Features

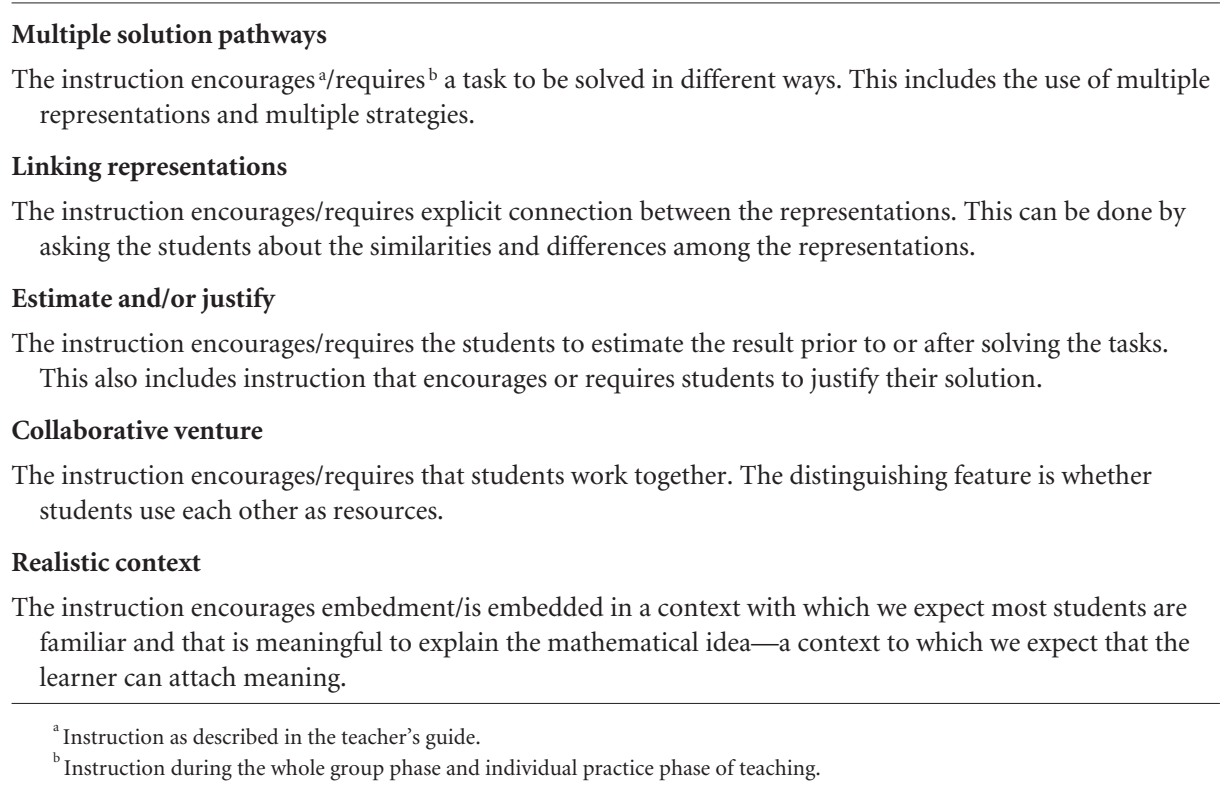

mended instructional features to have the potential to support the effective learning of fractions in a way that is in line with a view that stresses conceptual understanding rather than merely procedural fluency. These are tasks that (1) have to be solved through multiple solution pathways, (2) explicitly connect representations, (3) require students to estimate or justify their solution, (4) have to be solved in collaboration with other students, and (5) are embedded in realistic contexts.

Although literature also stressed the importance of connecting instruction to students' prior knowledge of fractions (e.g., Empson, 1995), we didn't analyze tasks on this additional instructional feature because we consider it to be part of the fifth recommended instructional feature-that tasks should be embedded in realistic contexts. Indeed, we see the use of realistic contexts as a means to build further on students' intuitive problem-solving abilities and prior knowledge. Another recurring recommended instructional feature is providing opportunities for students to discuss solutions. This recommended instructional feature was not included in the current analysis. We opted instead to include both information on the collaborative venture and whether students had to estimate or judge the result of an exercise. We do not want to disregard the importance of recommended instructional features that were omitted, but they were not the scope of the current study. Table 1 presents a description of each recommended instructional feature.

\section{Method}

\section{Data Sources}

Transcriptions of videotaped classroom lessons formed the basis of the data used for analysis. During Spring 2010, lessons were video-recorded by trained observers. 
Table 2. Overview of Selected Lessons

\begin{tabular}{|c|c|c|c|c|c|c|}
\hline & \multicolumn{3}{|c|}{ Included in the Analysis } & \multicolumn{3}{|c|}{ Mathematical Idea } \\
\hline & Lessons & Schools & Teachers & $F \& D$ & $\mathrm{C} \& \mathrm{O}$ & E. F. \\
\hline Kompas & 8 & 8 & 8 & 4 & 4 & - \\
\hline Nieuwe tal-rijk & 8 & 6 & 6 & 3 & 2 & 3 \\
\hline Zo gezegd, zo gerekend! & 8 & 6 & 6 & 1 & 2 & 5 \\
\hline Total & 24 & 20 & 20 & 8 & 8 & 8 \\
\hline
\end{tabular}

Note. $-\mathrm{F} \& \mathrm{D}=$ fractions and decimals $; \mathrm{C} \& \mathrm{O}=$ comparing and ordering fractions; E. F. = equivalent fractions.

Each observation covered one complete fourth-grade mathematics lesson ranging from 29 to 61 minutes long (average duration: 48 minutes).

The observers were students in educational sciences enrolled in the course "mathematics education" who were trained during two consecutive sessions. Observers were given information about the background and practical aspects of the study. Prior to collecting the data for the study, observers were given the opportunity to practice and received feedback. Between the first and second observation, and after the observations, observers met with other observers and the first author to share observations, obstacles, and other experiences with each other.

\section{Sampling Procedure}

Selection of teachers and lessons. Elementary schools in Flanders were randomly contacted and asked to participate in the study. A selection criterion that was checked during the initial contact with the schools related to whether schools used one of the most frequently used curriculum programs in Flanders: Kompas (KP), Nieuwe tal-rijk (NT), or Zo gezegd, zo gerekend! (ZG). The school principal and the fourth-grade teachers were informed about the aim of the study. In total, 22 schools participated in the study. From every school, one fourth-grade class was observed up to two times. This resulted in a total of 40 videotaped lessons. From this pool of 40 lessons, 24 were included in the present study. First, four lessons were not included due to incomplete video data. Reasons for incompleteness related to errors in the video data file that made part of the file unreadable, and not being able to follow conversations between the teacher and the students during the individual practice phase of teaching. Second, seven lessons were excluded from the analysis since they did not relate to fractions and decimals, comparing and ordering fractions, or equivalent fractions. Typically, these were lessons that focused on operations with fractions. From the remaining 29 lessons, an equal number of eight lessons per curriculum program were selected, covering the different mathematical ideas (fractions and decimals, ordering and comparing fractions, equivalent fractions) that we focus on in the present study. If we had a choice between lessons to include or exclude, we decided to exclude the lesson of a teacher that was already included in the analysis. Following this procedure, we ended up with 24 lessons to be analyzed (see Table 2). The 20 teachers had on average 12.8 years of teaching experience (range: 1-30) and 2.5 years of teaching experience with the curriculum in the current grade (range: $1-8$ ). In total, 342 students were involved in the study; class size ranged from 11 to 24 students. 


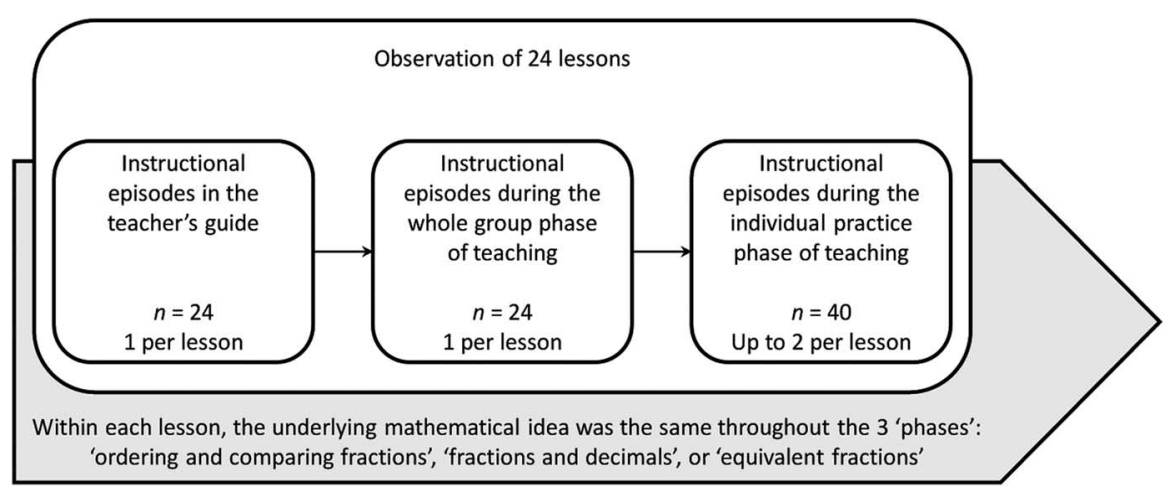

Figure 2. Overview of selected instructional episodes

Selection of instructional episodes. Fourteen lessons included one instructional episode during the whole group phase of teaching; five included two instructional episodes during the whole group phase of teaching, and another five included three instructional episodes during the whole group phase of teaching. For lessons with two or three instructional episodes during the whole group phase of teaching, the instructional episode that occupied the largest percentage of time was selected for analysis. For each selected instructional episode during the whole group phase of teaching, we identified its corresponding instructional episode in the teacher's guide. In addition, we selected up to two instructional episodes during the individual practice phase of teaching that also addressed the same mathematical idea as in the instructional episodes in the teacher's guide and during the whole group phase of teaching. As such, for each observed lesson, the underlying mathematical idea was the same for the instruction as described in the teacher's guide, during the whole group phase of teaching, and during the individual practice phase of teaching. This resulted in a total number of 88 instructional episodes to be analyzed ${ }^{4}$ (see Fig. 2).

Mathematical ideas included. As can be seen in Table 1 , the entire sample of lessons focused on three mathematical ideas within fractions: (1) the relationship between fractions and decimals (four lessons in KP, three in NT, one in ZG); (2) comparing and ordering fractions (four lessons in KP, two in NT, two in ZG); and (3) equivalent fractions (three lessons in NT, five in ZG). The first mathematical idea was conversion of fractions into decimals and decimals into fractions by means of base 10 blocks or an external number line, positioning fractions and decimals on a number line, and comparing fractions and decimals by means of area models. The second mathematical idea focused on comparing and ordering fractions by means of a number line or other representations. The third mathematical idea centered on finding equivalent fractions for a given fraction and on finding the most reduced form of a given fraction.

\section{The Context and the Curriculum Programs}

As in many other countries or regions, such as the United States, the prevailing view on mathematics education in Flanders, the Dutch-speaking part of Belgium, stresses the importance of teaching for conceptual understanding rather than focusing on memorizing formulas and applying procedures (Ministry of the Flemish Community Department of Education and Training, 1999; NCTM, 1989, 2000). This 
view is reflected in the standard-based curriculum programs adopted from the midto late 1990s, in Flanders as elsewhere.

Also, in Flanders as worldwide, students experience difficulty when learning fractions. The range of studies over the past years reveal that this problem is persistent. For example, two sample surveys, administered in Flanders in 2002 and 2009, revealed that on both measurement occasions, only $64 \%$ of the last-year Flemish elementary school students mastered the attainment targets—-minimum goals that all students should master at the end of elementary school, approved by the Flemish government-related to fractions and decimals (Ministry of the Flemish Community Department of Education and Training, 2010).

The three curriculum programs included in the study (KP, NT, ZG) embody-in line with the prevailing view on mathematics education - an approach to mathematics teaching and learning that was previously uncommon: focusing on mathematical thinking and reasoning, inclusion of problem-solving activities, making use of realistic contexts, the use of calculators, collaboration, communication, and the development of a critical attitude related to numerical information. All curriculum programs cluster lessons in a week, a block or theme addressing the main content domains of mathematics education: numbers and calculations, measurement, and geometry. Furthermore, as in many other countries, all curriculum programs consist of textbooks to be used by the students, and teacher's guides containing detailed guidelines to help teachers enact the lessons.

Given the extent to which the prevailing view of mathematics education in Flanders is aligned with those in many European countries and the United States, and given the other commonalities such as the use of textbooks and learning difficulties with fractions, classrooms in Flanders provide an opportunity to explore the evolution of instructional episodes during teaching.

\section{Coding}

Task coding. QSR NVivo 9 was used to code the selected instructional episodes. All video-recorded lessons were transcribed in detail to cover the conversations between the teacher and students. Coding was based on these transcriptions, and the corresponding video fragment was viewed only when the transcription did not provide sufficient information to make a decision. For each lesson, the instructional episodes in the teacher's guide, during the whole group phase of teaching, and during the individual practice phase of teaching were selected and coded. The coding scheme was based on the conceptual framework presented earlier and on the recommended instructional features (see Table 1) and was tested and revised until we ended up with the actual coding scheme (see Table 3). The coding scheme consists of five coding categories that describe the presence of the five recommended instructional features. We used one unique scheme for coding the instructional episodes in the teacher's guide, during the whole group phase of teaching, and during the individual practice phase of teaching, which follows the assertion by Stein et al. (2007) that the research field would benefit from establishing common structures for examining both the written curriculum and the enacted curriculum.

Decisions were made for each instructional episode related to the presence of the five recommended instructional features as mentioned above. All instructional episodes were coded by the first author. To ensure interrater reliability, a second re- 
Table 3. Overview of Codes That Can Be Assigned

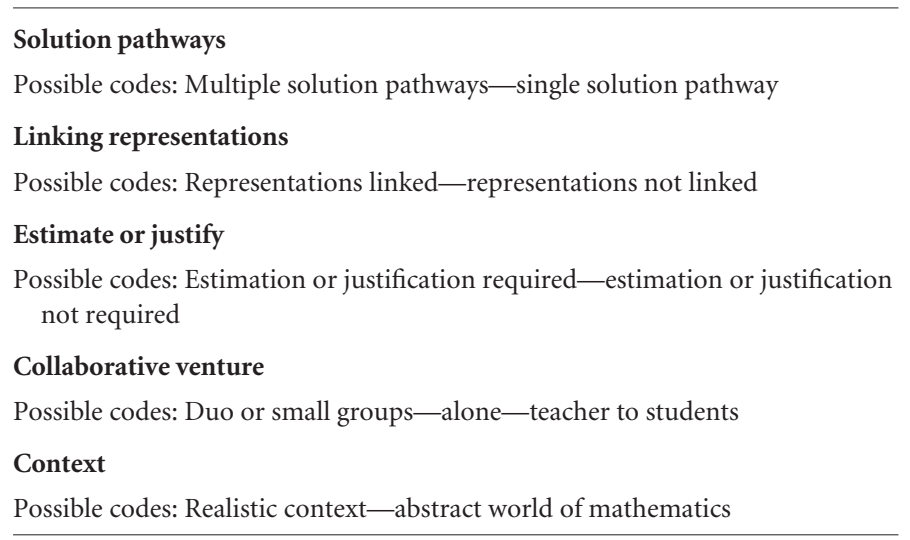

searcher was trained and asked to code three randomly selected lessons. To measure interrater reliability, Krippendorff's alpha was calculated for each decision to be made in the coding scheme and ranged from .80 to 1.00 and was as such above the customary border of $\alpha \geq .80$ (Krippendorff, 2009).

In order to examine patterns across the entire set of 24 lessons, we looked at the instructional features of (1) the 24 instructional episodes in the teacher's guide, (2) the 24 instructional episodes during the whole group phase of teaching, and (3) the 40 instructional episodes during the individual practice phase of teaching (see Fig. 2).

Coding criteria. Below we will describe the criteria we maintained to code these instructional episodes. Later in this article, in the analysis of a sample lesson, we will also illustrate how we applied these criteria in the current data set. Table 3 presents an overview of each of the codes that can be assigned for the five coding categories.

Coding of the selected instructional episodes in the teacher's guide related to whether this guide encouraged or suggested these instructional recommendations during teaching. Coding for selected instructional episodes during the whole group phase of teaching and the individual practice phase of teaching related to whether the instructional recommendations were included during instruction.

An instructional episode earned the code "multiple solution pathways" if it encouraged/required the use of multiple solution strategies or multiple representations. An example of the former is the partitioning of five pizzas among two friends (1) by allocating two whole pizzas to each friend and then giving each friend a half of the pizza that is left over, and (2) by dividing each of the five pizzas into halves and then allocating each friend five of the 10 pizza halves. An example of the latter is a task that focuses on finding equivalent fractions and does so both by means of an area model (e.g., a piece of paper) and a set model (e.g., a number of candies). It was not sufficient that instructional episodes encouraged/required multiple representations; these representations also needed to be suitable representations. An example of what would count as suitable representations is the representation of the unit by both an area model (e.g., a cookie) and a set model (e.g., an amount of candies) or by means of multiple set models (e.g., an amount of candies and a number of cards). Whereas area models can be useful in representing addition of fractions with positive numbers, they are not always so for addition of negative fractions (e.g., $3 / 4-5 / 6$ ). Therefore, in this specific case, the latter would not be considered a suitable representation. 
Given that research points to the importance of explicitly addressing links between representations (e.g., Cramer et al., 2002; Kazemi \& Stipek, 2001), only instructional episodes that explicitly encouraged/required students to connect representations were coded correspondingly. In the former example of multiple representations of the whole, the instructional episode would only be counted as linking representations if it explicitly addressed the connections between the representations, for example, by asking students questions about how the different representations of a whole relate to each other. Whereas some students might connect the representations by themselves even if this is not addressed explicitly, such instances were not assigned this specific recommended instructional feature.

Instructional episodes that encouraged/required students to estimate the result or to justify their solution were assigned the "estimate or justification" code. For instance, instruction that required students to estimate the sum of $1 / 2$ and $1 / 5$ was assigned this code. Likewise, if a student was required to explain her or his solution, the instructional episode also earned this specific recommended instructional feature.

The distinguishing criterion regarding the collaborative venture of an instructional episode is whether students were suggested/required to use each other as resources. Students placed in pairs to work on a task who were discussing with each other the approach to take in order to solve the task or the reasonableness of an outcome of that task were coded as "duo or small groups." If the same pair of students did not interact to discuss the approach to solve the task or the reasonableness of the result, then we assigned the code "alone."

To assign the code "realistic context," the instructional episode needed (to be suggested) to be embedded in a context that is meaningful and that we expect most students will be familiar with. Using a set of 24 playing cards is meaningful to explain that the fractions $1 / 4$ and $2 / 8$ are equivalent. This context is also familiar for a lot of students. However, the same set of cards would not be meaningful to help students understand the addition of $1 / 4$ and $4 / 5$. Likewise, using a piece of paper to be folded in equally-sized pieces can be meaningful to explain equivalence of fractions, but it is not a context with which we expect most students to be familiar.

Aggregation of instructional features. We will first explain how we obtained the values in Tables 4, 5, and 6, and then we will explain the values in Tables 7 and 8 . Each instructional episode in the teacher's guide was coded according to the presence or absence of each of the five recommended instructional features. Next, for each curriculum program and mathematical idea, we counted for each code-or instructional feature-how many instructional episodes in the teacher's guide were assigned that specific code/instructional feature. The numbers in Table 4 represent these values in percentages. The column "all instructional episodes" represents by means of percentages how many of all instructional episodes in the teacher's guide across all curriculum programs or mathematical ideas included the specific code/ instructional feature. The same procedure was applied to characterize instruction during the whole group phase of teaching (Table 5) and during the individual practice phase of teaching (Table 6).

Regarding the transition of instructional features when instruction unfolded from being represented in the teacher's guide to the whole group phase of teaching (see Table 7), we again calculated for each code/instructional feature how many instructional episodes in the teacher's guide included that specific code/instruc- 
Table 4. Presence of Instructional Features (in Percentages) as Described in the Teacher's Guide

\begin{tabular}{|c|c|c|c|c|c|c|c|}
\hline & \multicolumn{3}{|c|}{ Curriculum Program } & \multicolumn{3}{|c|}{ Mathematical Idea } & \multirow{2}{*}{$\begin{array}{c}\text { All } \\
\text { Instructional } \\
\text { Episodes } \\
(n=24)\end{array}$} \\
\hline & $\begin{array}{c}\mathrm{KP} \\
(n=8)\end{array}$ & $\begin{array}{c}\mathrm{NT} \\
(n=8)\end{array}$ & $\begin{array}{c}\mathrm{ZG} \\
(n=8)\end{array}$ & $\begin{array}{c}\text { F \& D } \\
(n=8)\end{array}$ & $\begin{array}{c}\mathrm{C} \& \mathrm{O} \\
(n=8)\end{array}$ & $\begin{array}{c}\text { E. F. } \\
(n=8)\end{array}$ & \\
\hline \multicolumn{8}{|l|}{ Solution pathway: } \\
\hline Single & 50 & - & - & 50 & - & - & 17 \\
\hline Multiple & 50 & 100 & 100 & 50 & 100 & 100 & 83 \\
\hline \multicolumn{8}{|l|}{ Representations-links: } \\
\hline Not linked & 50 & 100 & 22 & 100 & 25 & 38 & 54 \\
\hline Linked & 50 & - & 88 & - & 75 & 62 & 46 \\
\hline \multicolumn{8}{|l|}{ Estimation \& justification: } \\
\hline Not required & 100 & 88 & 50 & 75 & 100 & 62 & 79 \\
\hline Required & - & 12 & 50 & 25 & - & 38 & 21 \\
\hline \multicolumn{8}{|l|}{ Collaborative venture: } \\
\hline Alone & - & - & - & - & - & - & - \\
\hline Duo or small groups & - & - & 12 & - & 12 & - & 4 \\
\hline Teacher to students & 100 & 100 & 88 & 100 & 88 & 100 & 96 \\
\hline \multicolumn{8}{|l|}{ Context: } \\
\hline Abstract world of math & 100 & 100 & - & 88 & 75 & 38 & 67 \\
\hline Realistic context & - & - & 100 & 12 & 25 & 62 & 33 \\
\hline
\end{tabular}

Note.-KP = Kompas; $\mathrm{NT}=$ Nieuwe tal-rijk; ZG = Zo gezegd, zo gerekend!; F \& D = fractions and decimals; $\mathrm{C} \& \mathrm{O}=$ comparing and ordering fractions; E. F. = equivalent fractions.

tional feature. We did the same for the instructional episodes during the whole group phase of teaching. The results from the previous two steps where crosstabulated in a matrix containing all distinctive instructional features (or codes). Consequently, the cells represent the level of (in)consistency of instructional

Table 5. Presence of Instructional Features (in Percentages) during the Whole Group Phase of Teaching

\begin{tabular}{|c|c|c|c|c|c|c|c|}
\hline & \multicolumn{3}{|c|}{ Curriculum Program } & \multicolumn{3}{|c|}{ Mathematical Idea } & \multirow{2}{*}{$\begin{array}{c}\text { All } \\
\text { Instructional } \\
\text { Episodes } \\
(n=24)\end{array}$} \\
\hline & $\begin{array}{c}\mathrm{KP} \\
(n=8)\end{array}$ & $\begin{array}{c}\text { NT } \\
(n=8)\end{array}$ & $\begin{array}{c}\mathrm{ZG} \\
(n=8)\end{array}$ & $\begin{array}{c}\text { F \& D } \\
(n=8)\end{array}$ & $\begin{array}{c}\text { C \& O } \\
(n=8)\end{array}$ & $\begin{array}{c}\text { E. F. } \\
(n=8)\end{array}$ & \\
\hline \multicolumn{8}{|l|}{ Solution pathway: } \\
\hline Single & 50 & - & 12 & 62 & - & - & 21 \\
\hline Multiple & 50 & 100 & 88 & 38 & 100 & 100 & 79 \\
\hline \multicolumn{8}{|l|}{ Representations_-links: } \\
\hline Not linked & 88 & 50 & 88 & 88 & 50 & 88 & 75 \\
\hline Linked & 12 & 50 & 12 & 12 & 50 & 12 & 25 \\
\hline \multicolumn{8}{|l|}{ Estimation \& justification: } \\
\hline Not required & 62 & 62 & 50 & 75 & 50 & 50 & 58 \\
\hline Required & 38 & 38 & 50 & 25 & 50 & 50 & 42 \\
\hline \multicolumn{8}{|l|}{ Collaborative venture: } \\
\hline Alone & - & - & - & - & - & - & - \\
\hline Duo or small groups & - & - & - & - & - & - & - \\
\hline Teacher to students & 100 & 100 & 100 & 100 & 100 & 100 & 100 \\
\hline \multicolumn{8}{|l|}{ Context: } \\
\hline Abstract world of math & 62 & 75 & 12 & 88 & 38 & 25 & 50 \\
\hline Realistic context & 38 & 25 & 88 & 12 & 62 & 75 & 50 \\
\hline
\end{tabular}

Note.-KP = Kompas; NT = Nieuwe tal-rijk; ZG = Zo gezegd, zo gerekend!; F \& D = fractions and decimals; $\mathrm{C} \& \mathrm{O}=$ comparing and ordering fractions; E. F. = equivalent fractions. 
Table 6. Presence of Instructional Features (in Percentages) during the Individual Practice Phase of Teaching

\begin{tabular}{|c|c|c|c|c|c|c|}
\hline \multicolumn{3}{|c|}{ Curriculum Program } & \multicolumn{3}{|c|}{ Mathematical Idea } & \multirow{2}{*}{$\begin{array}{c}\text { All } \\
\text { Instructional } \\
\text { Episodes } \\
(n=40)\end{array}$} \\
\hline $\begin{array}{c}\mathrm{KP} \\
(n=11)\end{array}$ & $\begin{array}{c}\mathrm{NT} \\
(n=12)\end{array}$ & $\begin{array}{c}\mathrm{ZG} \\
(n=17)\end{array}$ & $\begin{array}{c}\mathrm{F} \& \mathrm{D} \\
(n=12)\end{array}$ & $\begin{array}{l}\mathrm{C} \& \mathrm{O} \\
(n=11)\end{array}$ & $\begin{array}{c}\text { E. F. } \\
(n=17)\end{array}$ & \\
\hline
\end{tabular}

\begin{tabular}{|c|c|c|c|c|c|c|c|}
\hline \multicolumn{8}{|l|}{ Solution pathway: } \\
\hline Single & 82 & 67 & 53 & 92 & 64 & 47 & 65 \\
\hline Multiple & 18 & 33 & 47 & 8 & 36 & 53 & 35 \\
\hline \multicolumn{8}{|l|}{ Representations_-links: } \\
\hline Not linked & 91 & 83 & 100 & 100 & 91 & 88 & 92 \\
\hline Linked & 9 & 17 & - & - & 9 & 12 & 8 \\
\hline \multicolumn{8}{|l|}{ Estimation \& justification: } \\
\hline Not required & 91 & 100 & 94 & 100 & 91 & 94 & 95 \\
\hline Required & 9 & - & 6 & - & 9 & 6 & 5 \\
\hline \multicolumn{8}{|l|}{ Collaborative venture: } \\
\hline Alone & 91 & 100 & 53 & 75 & 82 & 76 & 78 \\
\hline Duo or small groups & - & - & 6 & 8 & - & - & 2 \\
\hline Teacher to students & 9 & - & 41 & 17 & 18 & 24 & 20 \\
\hline \multicolumn{8}{|l|}{ Context: } \\
\hline Abstract world of math & 82 & 100 & 82 & 100 & 73 & 88 & 87 \\
\hline Realistic context & 18 & - & 18 & - & 27 & 12 & 13 \\
\hline
\end{tabular}

feature appearance (see Table 7). The same procedure was applied to analyze transition of instructional features when instruction moved from the whole group phase of teaching to the individual practice phase of teaching (see Table 8).

\section{A Sample Lesson on Equivalent Fractions and Its Coding}

In this section we provide the reader with an example of how our coding scheme was applied to a sample lesson. The section starts with a description and an analysis of the instruction as described in the teacher's guide. This is followed by a description and an analysis of the instruction during the whole group phase of teaching and the

Table 7. Matrix 1: Transition from Instructional Episodes in the Teacher's Guide to Instructional Episodes during the Whole Group Phase of Teaching

\begin{tabular}{|c|c|c|c|c|}
\hline \multirow[b]{3}{*}{ Instructional Episodes in Teacher's Guide } & \multicolumn{4}{|c|}{$\begin{array}{c}\text { Instructional Episodes during the Whole Group } \\
\text { Phase of Teaching }\end{array}$} \\
\hline & \multicolumn{2}{|c|}{ Solution Pathway } & \multicolumn{2}{|c|}{ Context } \\
\hline & Single & Multiple & $\begin{array}{l}\text { Abstract } \\
\text { World } \\
\text { of Math }\end{array}$ & $\begin{array}{l}\text { Realistic } \\
\text { Context }\end{array}$ \\
\hline \multicolumn{5}{|l|}{ Solution pathway: } \\
\hline Single $(n=4)$ & $100 \%(4)$ & o\% (o) & & \\
\hline Multiple $(n=20)$ & $5 \%(1)$ & $95 \%(19)$ & & \\
\hline \multicolumn{5}{|l|}{ Context: } \\
\hline Abstract world of math $(n=16)$ & & & $69 \%(11)$ & $31 \%(5)$ \\
\hline Realistic context $(n=8)$ & & & $13 \%(1)$ & $87 \%(7)$ \\
\hline
\end{tabular}


Table 8. Matrix 2: Transition from Instructional Episodes during the Whole Group Phase of Teaching to Instructional Episodes during the Practice Phase of Teaching

\begin{tabular}{|c|c|c|c|c|}
\hline \multirow{3}{*}{$\begin{array}{l}\text { Instructional Episodes during } \\
\text { the Whole Group Phase of } \\
\text { Teaching }\end{array}$} & \multicolumn{4}{|c|}{$\begin{array}{l}\text { Instructional Episodes during the Individual } \\
\text { Practice Phase of Teaching }\end{array}$} \\
\hline & \multicolumn{2}{|c|}{ Solution Pathway } & \multicolumn{2}{|c|}{ Context } \\
\hline & Single & Multiple & $\begin{array}{l}\text { Abstract World } \\
\text { of Math }\end{array}$ & Realistic Context \\
\hline \multicolumn{5}{|l|}{ Solution pathway: } \\
\hline Single $(n=10)$ & $\mathbf{9 0 \%}(9)$ & $10 \%(1)$ & & \\
\hline Multiple $(n=30)$ & $57 \%(17)$ & $43 \%(13)$ & & \\
\hline \multicolumn{5}{|l|}{ Context: } \\
\hline Abstract world of math $(n=18)$ & & & $100 \%(18)$ & o \\
\hline Realistic context $(n=22)$ & & & $77 \%(17)$ & $\mathbf{2 3} \%(5)$ \\
\hline
\end{tabular}

individual practice phase of teaching, respectively. The description of the sample lesson aims to familiarize the reader with the overall pattern in the instruction observed. It also helped us to set out our specific approach to analysis, which will be presented at the beginning of the Results section.

Description and Analysis of the Instruction as Described in the Teacher's Guide

This instructional episode in the teacher's guide encourages the teacher to start the lesson by informing the students that the lesson is about fractions. It then continues by directing action to finding equivalent fractions:

The students fold a piece of paper into two equal parts.

Ask the fractions questions:

What is the unit? (This piece of paper)

In how many equal parts did you divide the unit? (In two)

How big is each unit? $(1 / 2)$

Write the fraction $1 / 2$ on one of the two parts.

Continue working this way.

The students fold the piece of paper in four and eight equal pieces.

They will discover and say that $1 / 2$ of the piece of paper equals $2 / 4$ of the piece of paper and equals $4 / 8$ of the piece of paper.

The lesson description continues in a similar way to find equivalent fractions by means of 12 magnets and by means of fractions strips.

When we look back at the instruction in the teacher's guide, we ascertain that teachers are expected to teach students to find equivalent fractions in several ways: first, by revealing that these are fractions that represent an equally-sized piece of a piece of paper; second, by demonstrating that these are fractions that represent an equal number of magnets; and third, by pointing out that equivalent fractions represent the same length of a unit strip. The teachers thus are expected to teach students to find equivalent fractions through multiple solution pathways. Therefore, this excerpt was assigned the code "multiple solution pathways." At no time is the teacher expected to point students toward the ways in which the representations are different or similar, nor is the teacher encouraged to have students estimate or justify their 
answer. Therefore, the codes "representations not linked" and "estimation or justification not required" were assigned as well. Furthermore, the lesson description directs the teacher to steer the enactment: the teacher is expected to assign tasks and ask questions, and the students work them out on their own. No time is proposed to have students work in pairs or small groups. Therefore, the code "teacher to students" was applied. Finally, the lesson description does not make reference to a realistic context. Although students are familiar with a piece of paper, they do not typically use it to fold into equal-sized pieces. Therefore, the code "abstract world of mathematics" was applied.

\section{Description and Analysis of the Instruction during the Whole Group Phase of Teaching}

This excerpt describes the instructional episode during the whole group phase of teaching.

One morning after a break, students entered the classroom and were asked by the teacher whether some of them ate a cookie during the break. For the students who ate one, the teacher asked if they shared their cookie with a friend. None of them did. The teacher pointed to a student who ate a cookie and asked which part of the cookie the student would give to a hungry friend who wants an equal-sized part of the cookie. The student responded that he would give half a cookie to his friend. When asked the corresponding fraction by the teacher, the student answered $1 / 2$ (at the start of the lesson, the students were familiar with the part-whole notion of fractions, and by that moment, they also knew that the fraction $1 / 2$ corresponds with half a unit).

The teacher continued the lesson by handing out a piece of paper to each student and told them to think of the piece of paper as a cookie. The teacher explained that the piece of paper represented the unit and students were asked to show the piece of their cookie they would give to a friend if they both would eat an equalsized part of it. The students folded the paper in two equal-sized pieces and showed this to the teacher. The teacher asked them about the corresponding fraction. A student mentioned the fraction $1 / 2$; the other students were nodding. The teacher asked the student to justify his answer. The student showed his unfolded piece of paper and said that it represented the unit. He explained further that this unit is divided in two equal pieces of which he gave one to his friend. The teacher agreed and asked the students to show the size of the piece they would give to their friends if they had three friends instead of one who asked for a fair share of the cookie. The lesson carried on in a similar way.

Next the teacher asked them to think about how to fairly divide the four equalsized pieces of their cookie with one fiend, as two of the three friends turned out not to be hungry after all. The students showed the teacher two of the four equal-sized pieces and were then asked for the corresponding fraction (2/4). Again, the teacher asked them how they came to the answer. A student answered that one cookie represented the unit; this is now divided in four equal-sized pieces, and a fair share among the two friends corresponded with two of the four equal-sized pieces.

In a similar fashion, the lessons continued for the fraction $4 / 8$, and the teacher then asked them to think of the fractions $1 / 2,2 / 4$, and $4 / 8$ of the cookie. The 
students pointed out that in both cases they would eat the same size of the cookie, and the teacher referred to these fractions as being equivalent.

Next, the teacher pointed at 12 magnets on the blackboard and asked the students to think of these as 12 candies. The teacher pointed to the 12 candies as being the unit and a student was asked to take $2 / 3$ of the candies. The student had to justify his solution method while executing the task on the blackboard and came to the answer of 8 candies. The lesson continued in a similar fashion for $4 / 6$ of the candies, and the students noted that in both cases (taking away $2 / 3$ and $4 / 6$ of 12 candies), the answer was 8 candies, and thus $2 / 3$ of 12 candies equals $4 / 6$ of 12 candies. A student said that multiplying both the numerator and the denominator of the first fraction times two results in the second fraction. The teacher agreed and extended this finding by saying that it doesn't matter by how many times one multiplies the numerator and the denominator, as long as one multiplies them both with the same number. Next, the students applied this rule to a number of given fractions. The teacher then continued the instructional part of the lesson by having students find equivalent fractions by means of fractions strips.

When we look back on the part of this instructional episode during the whole group phase of teaching, we can observe that several of the recommended instructional features were present and others were not. Students were taught to find equivalent fractions by means of different representations. Also, the teacher built on the suggestion of a student to multiply both the numerator and denominator by two to find equivalent fractions. Therefore, the code "multiple solution pathways" was applied.

Furthermore, the different representations (a cookie, candies, fractions strips) were not linked explicitly to each other. Two important links seemed to be missing in the depicted instructional fragment. First, though at one point in the lesson the teacher referred to a cookie as being the unit and in another she referred to the 12 candies as being the unit, she did not state explicitly that a unit can be represented differently, for example, by a cookie or by 12 candies. Likewise, it was never explicitly stated that students could find an equivalent fraction for $1 / 2$ by making use of their cookie or their 12 candies or the fraction strips as representations. As such, the instructional episode was coded as not linking the representations.

When providing answers, the students were required to explain their thinking, to illuminate the strategy they adopted to come to an answer, and hence the instructional episode also earned the code "estimation or justification required." We also noted that throughout this instructional episode the teacher steered the enactment: the teacher assigned tasks and asked questions, and the students worked them out on their own. Although there were whole class moments in which a student explained how she/he got the answer, there were no moments in which the students really collaborated to come to an answer or used one another as resources; not in small groups, nor on whole class moments. Thus the code "teacher to students" was applied.

Finally, throughout the instructional episode, the folding of the paper and the sharing of the magnets were explicitly connected to situations in which students share cookies and candies. The students also referred to the piece of paper and the magnets as cookie and candies. We argue that this instructional episode was embedded in a context that is familiar for students and meaningful to help students under- 
stand the meaning of equivalent fractions. Therefore, the code "realistic context" was applied.

Description and Analysis of the Instruction during the Individual Practice Phase of Teaching

After the whole group phase of teaching, the lesson continued as follows:

Students' practice books were handed out and students were told by the teacher on which pages they had to open their books. The teacher then guided the students through the first of the tasks in the practice book. The first task consisted of six exercises. The teacher asked the students what the task required them to do (to find equivalent fractions for a shaded part of a square). They solved two exercises together, and the students were then instructed to complete the rest of the exercises on their own. They were also told that in case of difficulties they could ask the teacher for help. The students then completed the exercises on their own and raised their hand when they wanted the teacher to help them. In a moment during which the teacher helped a student and that is typical for the help provided during the individual practice phase of teaching, the teacher helped the student to find an equivalent fraction for the fraction 3/12. The teacher proposed finding a more reduced form of the fraction and told the student that he should divide both the numerator and denominator by three. The student then gave $1 / 4$ as a response. The teacher agreed and told the student that it is recommended to divide both numerator and denominator by a number as big as possible. The student nodded and the teacher continued her way through the classroom. At the end of the lesson, the students handed in their practice book, placed their chairs on their desks, and left the classroom.

When looking back on this instructional episode during the individual practice phase of teaching, we see that when the teacher helped a student in finding an equivalent fraction for $3 / 12$, she pointed to applying a rule, namely, dividing both the numerator and denominator by the same number. She did not refer to other solution pathways that the students explored during the whole group instructional phase of teaching. Hence, the code "single solution pathway" was assigned. Representations were not linked to each other and the student was also not required to justify or explain the solution method; thus the codes "representations not linked" and "estimation or justification not required" were assigned. The student worked on his own and there was no reference made to realistic contexts, and thus the codes "alone" and "abstract world of mathematics" were assigned as well. This is in sharp contrast to the codes/task features that were present during the whole group instruction phase of teaching (i.e., multiple solution pathways, estimate or justify the solution, and realistic contexts). Obviously, there was a sharp decline in features as the lesson moved from the whole group phase of teaching to the individual practice phase of teaching.

\section{Results}

The characteristics of the sample lesson as presented in the previous section represent several patterns found across the entire set of 24 lessons that we discuss 
below. To do so, we will first present the structure of the lessons that we observed. In the section "Instructional Features" we will analyze the presence of the five recommended instructional features in the teacher's guide, during the whole group phase of teaching and during the individual practice phase of teaching. In the next section ("Change of Instructional Features"), we will analyze the specific transition of instructional features as instruction moves from the teacher's guide to the whole group phase of teaching and to the individual practice phase of teaching.

\section{Structure of Observed Lessons}

All 24 observed lessons started with a short introduction during which the teacher identified the subject of the lesson and instructed students to retrieve required materials (e.g., textbooks, pencils, or other tools). On occasion, the teacher reviewed previously taught content. The introduction was always followed by a whole class instruction period that was strongly guided by the teacher (i.e., "whole group phase of teaching"). Typically, the whole group phase of teaching addressed teaching of new content or teaching of previously learned content by means of step-by-step teacher-steered guidance. Next, students practiced the taught content on their own and were-if they encountered problems - helped individually by the teacher (i.e., "individual practice phase of teaching"). Lessons were closed by collecting textbooks; during two observations, closing of the lesson also comprised a summary of the learned content.

Introduction ranged from 20 seconds to 11 minutes and covered on average $4 \%$ of the lesson. The whole group phase of teaching ranged from 8 to 40 minutes and covered on average $49 \%$ of the total lesson duration. Coded instructional episodes during the whole group phase of teaching ranged from 6 to 40 minutes, with an average length of 20 minutes. On average the coded instructional episode covered $85 \%$ of the total whole group phase of teaching. The individual practice phase of teaching ranged from 3 to 40 minutes and covered on average $44 \%$ of the lesson. Closing ranged from o to 5 minutes and covered on average $1 \%$ of the lesson. Two percent of total lesson duration was coded as not related to mathematics. This included moments in which a colleague of the teacher entered the class and had a conversation with the teacher and moments in which the teacher left the classroom.

We also observed some deviations from this general pattern. In two of the 24 observed lessons, there were no instances during which the teacher helped students experiencing difficulties during practice time; only students who knew the answer to the problems were given the opportunity to answer during the practice time in these two whole class lessons. In another lesson, the whole group phase of teaching took nearly the complete lesson time, and there was no time to start practice. Finally, in yet another lesson, when helping a student with problems during the individual practice phase of teaching, the teacher did include realistic contexts, pointed at multiple solution pathways, and linked the representations to each other. Despite these exceptions, the pattern described as above counted for most of the lessons. 


\section{Instructional Features}

In next three subsections, we analyzed the presence of the five recommended instructional features in the teacher's guide, during the whole group phase of teaching, and during the individual practice phase of teaching.

Instructional episodes in the teacher's guide. Table 4 gives an overview of the instructional features of all 24 coded instructional episodes in the teacher's guide by curriculum program and mathematical idea of the lesson. We first looked for a general pattern in those 24 coded instructional episodes (see column "All Instructional Episodes" in Table 4). This overall picture revealed mixed findings related to the presence of the five recommended instructional features. The majority of the instructional episodes stressed the use of multiple solution pathways $(83 \%)$. However, more than half of the 24 instructional episodes did not suggest linking the multiple representations to each other (54\%); most instructional episodes did not require students to estimate or justify their solution ( $79 \%)$, did not stimulate collaboration between students ( $96 \%)$, and also remained in the abstract world of mathematics $(67 \%)$.

Given that curriculum programs are considered a main source for instruction, we made a comparison of the presence of instructional features in the three curriculum programs (see the columns "KP," "NT," "ZG" in Table 4). Instructional episodes represented in the teacher's guide of $Z G$ were most in line with what is recommended by research: ZG suggested more than NT and KP to link representations, estimate or justify the solution, have students working together in pairs or in small groups, and include realistic contexts. All instructional episodes in ZG and NT suggested multiple solution pathways. NT did somewhat better than KP: NT suggested more than KP to use multiple solution pathways and estimate and justify the result; KP suggested to link representations more than NT did. Both NT and KP did not suggest having students work together in pairs or small groups or to include realistic contexts.

When we made a comparison based on the underlying mathematical idea of the coded instructional episode (see the columns "F \& D," "C \& O," and "E. F." in Table 4), the following picture emerges. Instructional episodes that related to fractions and decimals contrasted with instructional episodes that related to comparing and ordering fractions, and equivalent fractions in their way of limited alignment with what is recommended by research. Only half of the instructional episodes suggested multiple solution pathways, and all or most did not encourage linking representations, estimate or justify the solution, have students working together in pairs or small groups, or making use of realistic contexts. There were no remarkable differences related to comparing and ordering fractions and equivalent fractions. Both did better for two recommended features (equivalent fractions: estimating or justifying the solution and inclusion of realistic contexts; comparing and ordering fractions: linking representations, having students working together in pairs or small groups). All instructional episodes related to equivalent fractions, and comparing and ordering fractions suggested multiple solution pathways.

Instructional episodes during the whole group phase of teaching. Table 5 gives an overview of the features of all 24 coded instructional episodes during the whole group phase of teaching. Again, we first looked for a general pattern based on all 24 coded instructional episodes (see column "All Instructional Episodes" in Table 5). 
The overall picture revealed a similar pattern as observed in the teacher's guide. The majority of the instructional episodes required the use of multiple solution pathways $(79 \%)$. Most or all instructional episodes did not require linking the representations to each other $(75 \%)$, estimating or justifying the solution $(58 \%)$, or having students work together in pairs or small groups $(100 \%)$. Half of the instructional episodes were embedded in a realistic context.

A comparison based on the three curriculum programs (see the columns "KP," "NT," and "ZG" in Table 5) again revealed a similar pattern as in the analysis of instructional episodes in the teacher's guide. None of the instructional episodes required students to work in pairs or in small groups. Instructional episodes that related to ZG included mostly multiple solution pathways and a realistic context. Half of the instructional episodes that related to ZG required estimating or justifying the solution, and they mostly did not require students to link the representations. All instructional episodes that related to NT included multiple solution pathways, and most often required students to link the representations. They mostly did not require students to estimate or justify the solution and they also mostly did not include a realistic context. Half of the instructional episodes that related to KP included multiple solution pathways. Most of the instructional episodes that related to KP did not require students to link representations or to estimate or justify the solution, and did not include a realistic context.

When we made a comparison based on the underlying mathematical idea of the coded instructional episode (see the columns "F \& D," "C \& O," and "E. F." in Table 5), a similar picture as in the previous section emerged. Instructional episodes that related to fractions and decimals contrasted with instructional episodes that related to comparing and ordering fractions and equivalent fractions in their limited alignment with the recommended instructional features. Most of the instructional episodes that related to fractions and decimals did not include multiple solution pathways and did not require students to link representations, to estimate or justify the solution, to work together in pairs or small groups, and did not include a realistic context.

Again, there were no straightforward differences related to comparing and ordering fractions and equivalent fractions. They scored equally on three recommended instructional features (multiple solution pathways, requiring students to estimate or judge the result, requiring students to work in pairs or small groups). Both did better on one recommended feature (equivalent fractions: inclusion of realistic contexts; comparing and ordering fractions: linking representations).

Instructional episodes during the individual practice phase of teaching. Table 6 gives an overview of the features of all 40 coded instructional episodes during the individual practice phase of teaching. Again, we first looked for a general pattern based on all 40 coded instructional episodes (see column "All Instructional Episodes" in Table 6). The results revealed that a majority of instructional episodes focused on a single solution pathway $(65 \%)$, did not link representations to each other (92\%), did not require students to justify their answer (95\%), did not require students to collaborate ( $98 \%$ ), and remained in the abstract world of mathematics $(87 \%)$.

A comparison based on the three curriculum programs (see the columns "KP," "NT," and "ZG" in Table 6) revealed an absence of straightforward differences. Instructional episodes during the practice phase of teaching when working with KP, 
NT, or ZG reflected to a similar extent instructional features that were not in line with what is recommended by research: most instructional episodes from either KP, NT, or ZG focused on a single solution pathway and did not require students to link representations to each other, to estimate or justify the solution, to work together in pairs or small groups, and did not include realistic contexts.

When we made a comparison based on the underlying mathematical idea of the coded instructional episode (see the columns "F \& D," "C \& O," and "E. F." in Table 6), a similar picture as in the previous sections emerged. Once again, instructional episodes that related to fractions and decimals contrasted with instructional episodes that related to comparing and ordering fractions and equivalent fractions in their limited alignment with the recommended instructional features. It should be stated, however, that also for instructional episodes that related to comparing and ordering fractions and equivalent fractions, presence of recommended instructional features was low.

The analysis of instructional episodes in the teacher's guide, during the whole group phase of teaching and during the individual practice phase of teaching, revealed that the instructional features of instructional episodes in the teacher's guide resembled the instructional features of instructional episodes during the whole group phase of teaching. This was not the case regarding the instructional features for instructional episodes during the whole group phase of teaching and during the individual practice phase of teaching. To study this more deeply, we analyzed the specific transition of an instructional episode moving from the teacher's guide to the whole group phase of teaching to the individual practice phase of teaching. This is the focus of the next section.

\section{Change of Instructional Features}

In order to analyze the extent to which instructional features change as instruction unfolds from the teacher's guide to the whole group phase of teaching to the individual practice phase of teaching, two matrices were generated. The first matrix (see Table 7) captures consistency in transition from instructional episodes in the teacher's guide to the instructional episodes during the whole group phase of teaching. The row headings list the codes assigned to the instructional episodes in the teacher's guide, and the column headings list the codes for the corresponding instructional episodes during the whole group phase of teaching. The second matrix (see Table 8) captures consistency in transition from instructional episodes during the whole group phase of teaching to the instructional episodes during the individual practice phase of teaching. The row headings list the codes assigned to the instructional episodes during the whole group phase of teaching, and the column headings list the codes for the corresponding instructional episodes during the individual practice phase of teaching. Each cell contains the corresponding percentage and frequency. Percentages on the diagonals of the matrices represent consistency between (1) the instructional features of instructional episodes in the teacher's guide and the corresponding instructional episodes during the whole group phase of teaching (matrix 1) and (2) instructional features of instructional episodes during the whole group phase of teaching and the corresponding instructional episodes during the individual practice phase of teaching (matrix 2). Off-diagonal cells represent inconsistencies. 
Matrix 1 revealed a high level of consistency between the instructional episodes in the teacher's guide and the corresponding instructional episodes during the whole group phase of teaching: percentages on the diagonal ranged from $69 \%$ to $100 \%$. For example, $95 \%$ of all the instructional episodes in the teacher's guide that were coded as stressing multiple solution pathways were also coded alike during the whole group phase of teaching.

Matrix 2 revealed a different pattern compared to the pattern observed in matrix 1. Percentages on the diagonal were high for instructional features that are not suggested by research: focus on a single solution pathway, remaining in the abstract world of mathematics. For example, $90 \%$ of all the instructional episodes during the whole group phase of teaching that focused on a single solution pathway were also coded alike during the individual practice phase of teaching. This revealed a consistency between instructional episodes during the whole group phase of teaching and the corresponding instructional episodes during the individual practice phase of teaching regarding instructional features that are not suggested by research. Percentages on the off-diagonal cells were high for the recommended instructional features. For example, $57 \%$ of all the instructional episodes that focused on multiple solution pathways during the whole group phase of teaching were coded as focusing on a single solution pathway during the individual practice phase of teaching. This revealed an inconsistency regarding presence of the recommended instructional features of instructional episodes during the whole group phase of teaching and during the individual practice phase of teaching.

\section{Discussion}

The study revealed that limited attention was devoted to three of the five recommended instructional features across the instructional episodes in the teacher's guide, during the whole group phase of teaching and during the individual practice phase of teaching. Despite the fact that research pointed to the importance of having students actively collaborate with one another (e.g., Cramer et al., 2002; Kazemi \& Stipek, 2001), the current study clearly provides evidence that students worked mostly under clear steering by the teacher during the whole group phase of teaching and individually during the practice phase of teaching. Collaborative learning about fractions barely occurred during the parts of the curriculum implementation chain that we studied. Further, treating mathematical connections in an explicit way is described as an important aspect of instruction as it aims to improve students' conceptual understanding (Cramer et al., 2002; Hiebert \& Grouws, 2007). Once again, moments in which representations were explicitly linked to each other were seldom observed throughout all parts of the curriculum implementation chain that we studied. Moments in which students were required to estimate the answer or justify their solution method were also very scarce. This is in spite of the fact that research has shown that this task feature can be helpful when teaching fractions for conceptual understanding (Siegler et al., 2010). A stronger focus on each of these three recommended instructional features throughout the curriculum implementation chain might strengthen the conceptually oriented focus when teaching fractions.

We further noticed a number of factors that contributed to a departure from the recommended instructional units. First, the results revealed differences in the use of recommended instructional features related to the three curriculum programs (KP, 
NT, ZG). Although there was some overlap between curriculum programs and mathematical ideas (see "Sampling Procedure"), we did notice interesting trends. $\mathrm{KP}$, for instance, contrasted with ZG and NT in the inclusion of recommended instructional features in the teacher's guide and during the whole group phase of teaching. There were no straightforward differences between curriculum programs for instruction during the practice phase of teaching. A closer look at the teacher's guides suggested that this might be due to the limited amount of support that they provided related to the individual practice phase of teaching. Besides providing information on what to do, and, in some cases, which representations might be helpful, the guides provide little, if any, guidance related to the individual practice phase of teaching. A more elaborated description in the guides about how to help students during the individual practice phase of teaching is thus recommended.

A second factor concerned the specific fractions subtopic, or mathematical idea, that was the focus of the instruction. Instruction that related to fractions and decimals included consistently fewer recommended instructional features compared to instruction that related to comparing and ordering fractions and equivalent fractions. We observed this for instruction as described in the teacher's guide, during the whole group phase of teaching and during the individual practice phase of teaching. This is striking, especially because some of the task features (use of visual representations, providing opportunities to use estimation to predict or judge the result, and embedment in realistic contexts) are considered to be helpful, especially in the teaching and learning of decimals (Irwin, 2001; Rittle-Johnson et al., 2001; Schneider et al., 2009; Siegler et al., 2010). This finding suggests that more attention to the recommended instructional features is especially needed when teaching about the relationship between fractions and decimals.

A third factor concerned the transition of instruction during the whole group phase of teaching to the individual practice phase of teaching. For the two recommended instructional features that were to a greater extent present in instruction during the whole group phase of teaching (i.e., multiple solution pathways and embedment in a realistic context), transition matrix 2 revealed that the inclusion of these recommended instructional features diminished sharply during the individual practice phase of teaching. This may be due to the specific teaching practice (i.e., a whole group phase of instruction followed by an individual practice phase of instruction): perhaps teachers did not expect that a continued focus on the recommended instructional features is needed during practice of content that was taught during the whole group phase of teaching. It may also be related to the particular students that are helped during the individual practice phase of teaching. Typically, these are students that experience difficulties. It is possible that for those students with difficulties teachers considered it especially important that they be able to come up with a correct answer. This would correspond to what Stein et al. (1996) noted, namely, that teachers might shift focus from the solution process to correctness of the answer.

From a methodological perspective, the concept of instructional episode as a unit of analysis helped to analyze something as complex as the teaching of fractions in Flanders. The distinction between instruction as presented in the teacher's guide, instruction during the whole group phase of teaching, and instruction during the individual practice phase of teaching was also useful since it helped to describe the process of instruction as it unfolded in the class. 
Although we addressed the teaching of fractions in Flanders, we believe that the findings are potentially interesting for other subjects within mathematics education and for other regions or countries. Future research could analyze, for example, the presence of (other) recommended instructional features when teaching other subjects within the number domain, such as addition and subtraction of decimals, multiplication and division of whole numbers, or algebra. This could reveal to what extent the factors that contributed to a departure from the recommended instructional features in the current study are more broadly applicable.

As to the limitations of the study, we should mention that we did not study the cognitive demands of the tasks. Also, whereas Stein et al. (2007) asked for studies that addressed the whole curriculum implementation chain (written, intended, enacted curriculum, and student learning), the current study did not focus on the intended curriculum - this refers to the teacher's plans for instruction. The assistance provided by the teacher to students who are struggling is considered to be a mediating variable between the task as set up by the teacher and the task as implemented by the students (Stein et al., 1996) and was also addressed in this study during the individual practice phase of teaching. However, we did not control for other variables such as teachers' knowledge of fractions or teachers' orientations toward the curriculum that might explain transformations between the different phases of the curriculum chain as depicted in the conceptual framework.

Also, there are off course other important instructional features related to the teaching of fractions that were not included in the current analysis (e.g., building on students' prior knowledge, providing opportunities to really discuss solutions, posing nonroutine and open-ended questions, elaborating on students' errors to help them reconceptualize knowledge). Although we addressed some of these features indirectly (i.e., building on students' prior knowledge, discussing solutions), others were left out of the scope of the current analysis. Other studies might also include these variables, the intended curriculum, and students' performance in the analysis.

Finally, although in general the recommended instructional features had a tendency to decline from instruction during the whole group phase of teaching to the individual practice phase of teaching, we also noted some deviations to this pattern. Future research might focus on instances in which inclusion of the recommended instructional features rises as instruction unfolds from the whole group phase of teaching to the individual practice phase of teaching. It might be useful for both research and practice to understand why or what made these teachers introduce these desired features at times when students are experiencing difficulties.

\section{Conclusion}

The applied conceptual framework, which was adapted to fit a context-specific teaching structure, proved to be useful in analyzing the complex nature of teaching fractions. This study revealed that the sample of observed lessons on fractions in Flanders reflected to a limited extent the contemporary recommendations from research on the teaching and learning of fractions. We also revealed influential factors that contributed to a departure from these recommendations.

The findings further confirmed that curriculum programs are a main source of instruction in the class (Stein et al., 2007) and, in addition, stressed the differentiating role of the specific subtopic of the lesson regarding inclusion of the recommended 
instructional features. It was not sufficient to look at the topic of the lessons (i.e., fractions), but it was necessary to look in more detail into the specific subtopic of the lesson.

\section{Notes}

Hendrik Van Steenbrugge is a postdoctoral researcher at Mälardalen University; Janine Remillard is a professor at the University of Pennsylvania; Lieven Verschaffel is a professor at the Katholieke Universiteit Leuven; Martin Valcke and Annemie Desoete are professors at Ghent University. Correspondence may be sent to Hendrik Van Steenbrugge at hendrik.van.steenbrugge@mdh.se.

1. For example, Australian Education Council, 1990; Ministry of the Flemish Community Department of Education and Training, 1999; NCTM, 1989; Office for Standards in Education, 1994; Swedish National Agency for Education, 2011.

2. More than half of the tasks related to reform-inspired topics (e.g., statistics, algebra, geometry); most of the remaining tasks were more conventional in character (e.g., whole number operations, changing from fractions to decimals and vice versa). A minority of tasks related more to mathematical processes than to a specific topic. In total, $39 \%$ of the tasks were from sixth-grade classes, $38 \%$ from seventh-grade classes, and $24 \%$ from eighth-grade classes.

3. Of the three above mentioned studies, only the study by Cramer et al. (2002) was included in the review study. Siegler et al. (2010) identified only 33 studies that met the What Works Clearinghouse standards. Given the limited number of studies, Siegler et al. (2010) also included a number of other studies that were relevant for the recommendations. It appeared that the studies of Gearhart et al. (1999) and Kazemi and Stipek (2001) were not included in the final selection of studies to be reviewed.

4. For 18 of the 24 selected tasks as set up by the teacher, two instructional episodes during the individual practice phase of teaching were selected. For four lessons, we could not select instructional episodes during the individual practice phase of teaching because instruction took the major portion of the lesson and practice was too short to allow for selecting two tasks. In one lesson, we selected three instructional episodes during the individual practice phase of teaching in order to cover to whole range of instructional episodes during the individual practice phase of teaching. In yet another lesson, we selected only one instructional episode during the individual practice phase of teaching.

\section{References}

Australian Education Council. (1990). A national statement on mathematics for Australian schools. Canberra: Curriculum Corporation.

Boaler, J., \& Staples, M. (2008). Creating mathematical futures through an equitable teaching approach: The case of Railside School. Teachers College Record, 110(3), 608-645.

Cramer, K. A., Post, T. R., \& delMas, R. C. (2002). Initial fraction learning by fourth- and fifthgrade students: A comparison of the effects of using commercial curricula with the effects of using the rational number project curriculum. Journal for Research in Mathematics Education, 33(2), 111-144. doi:10.2307/749646

Doyle, W. (1983). Academic work. Review of Educational Research, 2(53), 159-199.

Empson, S. B. (1995). Research into practice: Using sharing situations to help children learn fractions. Teaching Children Mathematics, 2, 110-114.

Gearhart, M., Saxe, G. B., Seltzer, M., Schlackman, J., Ching, C. C., Nasir, N. I., . . Sloan, T. F. (1999). Opportunities to learn fractions in elementary mathematics classrooms. Journal for Research in Mathematics Education, 30(3), 286-315.

Hiebert, J., \& Grouws, D. A. (2007). The effects of classroom mathematics teaching on students' learning. In F. K. Lester (Ed.), Second handbook of research on mathematics teaching and learning (pp. 371-404). Greenwich, CT: Information Age.

Irwin, K. C. (2001). Using everyday knowledge of decimals to enhance understanding. Journal for Research in Mathematics Education, 32(4), 399-420. doi:10.2307/749701 
Kazemi, E., \& Stipek, D. (2001). Promoting conceptual thinking in four upper-elementary mathematics classrooms. Elementary School Journal, 102(1), 59-80.

Krippendorff, K. (2009). Testing the reliability of content analysis data: What is involved and why. In K. Krippendorff \& M. A. Bock (Eds.), The content analysis reader (pp. 350-357). Thousand Oaks, CA: Sage. Retrieved from http://www.asc.upenn.edu/usr/krippendorff/dogs.html.

Lamon, S. J. (2007). Rational numbers and proportional reasoning. In F. K. Lester (Ed.), Second handbook of research on mathematics teaching and learning (pp. 629-667). Greenwich, CT: Information Age.

Ma, L. (1999). Knowing and teaching elementary mathematics: Teachers' understandings of fundamental mathematics in China and the United States. Mahwah, NJ: Erlbaum.

Ministry of the Flemish Community Department of Education and Training. (1999). Basisonderwijs: ontwikkelingsdoelen en eindtermen [Attainment targets in elementary school]. Brussels: Ministerie van de Vlaamse Gemeenschap, Departement Onderwijs.

Ministry of the Flemish Community Department of Education and Training. (2010). Tweede peiling wiskunde in het basisonderwijs [Second sample survey of mathematics in elementary school]. Brussels: Ministerie van de Vlaamse Gemeenschap, Departement Onderwijs.

NCTM. (1989). Curriculum and evaluation standards for school mathematics. Reston, VA: Author.

NCTM. (2000). Principles and standards for school mathematics. Reston, VA: NCTM.

Newton, K. J. (2008). An extensive analysis of preservice elementary teachers' knowledge of fractions. American Educational Research Journal, 45 (4), 1080-1110. doi:10.3102/0002831208320851

Office for Standards in Education. (1994). Science and mathematics in schools: A review. London: Her Majesty's Stationary Office.

Pepin, B., \& Haggarty, L. (2001). Mathematics textbooks and their use in English, French, and German classrooms: a way to understand teaching and learning cultures. International Journal on Mathematics Education (ZDM), 33(5), 158-175.

Remillard, J. T., \& Bryans, M. B. (2004). Teachers' orientations toward mathematics curriculum materials: implications for teaching learning. Journal for Research in Mathematics Education, 35(5), 352-388.

Rittle-Johnson, B., Siegler, R. S., \& Alibali, M. W. (2001). Developing conceptual understanding and procedural skill in mathematics: An iterative process. Journal of Educational Psychology, 93(2), 346-362. doi:10.1037/0022-0663.93.2.346

Schneider, M., Grabner, R. H., \& Paetsch, J. (2009). Mental number line, number line estimation, and mathematical achievement: Their interrelations in grades 5 and 6. Journal of Educational Psychology, 101(2), 359-372. doi:10.1037/aoo13840

Siegler, R., Carpenter, T., Fennell, F., Geary, D., Lewis, J., Okamoto, Y., . . W Wray, J. (2010). Developing effective fractions instruction for kindergarten through eighth grade: A practice guide (NCEE\#2010-4039). Washington, D.C.: National Center for Education Evaluation and Regional Assistance, Institute of Educational Sciences, U.S. Department of Education.

Sophian, C., Garyantes, D., \& Chang, C. (1997). When three is less than two: Early developments in children's understanding of fractional quantities. Developmental Psychology, 33 (5), 731-744.

Stein, M. K., Grover, B. W., \& Henningsen, M. (1996). Building student capacity for mathematical thinking and reasoning: An analysis of mathematical tasks used in reform classrooms. American Educational Research Journal, 33(2), 455-488. doi:10.3102/00028312033002455

Stein, M. K., \& Lane, S. (1996). Instructional tasks and the development of student capacity to think and reason: an analysis of the relationship between teaching and learning in a reform mathematics project. Educational Research and Evaluation, 2, 50-80.

Stein, M. K., Remillard, J., \& Smith, M. S. (2007). How curriculum influences student learning. In F. K. Lester (Ed.), Second handbook of research on mathematics teaching and learning (pp. 319370). Greenwich, CT: Information Age.

Stigler, J., \& Hiebert, J. (2004). Improving mathematics teaching. Educational Leadership, 61(5), $12-16$.

Streefland, L. (1991). Fractions in realistic mathematics education: A paradigm of developmental research. Dordrecht, The Netherlands: Kluwer.

Swedish National Agency for Education. (2011). Curriculum for the compulsory school, preschool class and the leisure-time centre 2011. Retrieved 02/04/2013, from www.skolverket.se/publikationer 